\title{
Effect of a Static Var Compensator on an Electrical Power Transmission System
}

\author{
Aaron Don M. Africa, Juan Miguel C. Lacanilao, Ray Vincent Alin B. Lamdagan \\ Department of Electronics and Communications Engineering \\ De La Salle University, Manila \\ 2401 Taft Ave., Malate, Manila 1004, \\ Philippines, aaron.africa@dlsu.edu.ph
}

\begin{abstract}
Electricity in the present time is pretty much a necessity hence the need for more supply to cover every household. Due to the increase in electric power demand, there is a need for long-distance, large power transmission lines. Given the increase in power distribution, the new transmission lines still need to meet quality standards. Considering that developing a new transmission line is costly and time-consuming, an alternative solution is required. This research aims to show the effects of a Static Var Compensator (SVC) on how it can improve the voltage of a transmission system. An SVC is a set of electrical devices that provide fast-acting reactive power on high-voltage electricity transmission networks. Using MATLAB/Simulink, we will design and simulate a transmission system with an SVC under different cases of varying loads. The data gathered will then be compared to see the effect of the SVC on a transmission system. Results should show that there should be a voltage improvement when an SVC is present in the transmission system.
\end{abstract}

Key words: Static Var Compensator, Transmission System, MATLAB/Simulink, Voltage Improvement.

\section{INTRODUCTION}

Electricity is one of the essential needs of a household due to the unlimited applications it can provide. The latest technologies now greatly depend on electricity to accommodate humans to make their lives easier. Electricity is an exceptionally powerful element and since it has unlimited applications, it also possesses unlimited complications. In communications engineering, the transmission line is one of the most important components to consider especially in design structures. One of the most common issues transmission lines can encounter is maintaining power while under data transmission.

Transmission lines have numerous applications and one of which is that it is used widely in communications. The transmission line is an important component in communications since it is the most appropriate medium for transmission over long or short distances with minimal interference. Televisions and radios mainly depend on transmission lines to transmit information through a large area.

The loss of power in transmission lines can greatly affect millions of households due to the reliability of humans to the applications of electricity [1]. In devices, the length of wires connecting various components is also one of the problems devices can encounter which is commonly ignored. The length of the wires can affect the amount of time voltage travels from each component to the other. Though minimal, the length of the wire is important because the signals included in the transmission lines have frequency components with correlation to the wavelengths in comparison to the length of the wire. Another aspect to consider is that transmission lines consist of minimal amounts of impedance that could affect the power loss in transmission lines especially when considering long-distance transmission. In consideration, the wavelength of the signal in transmission lines is different to the corresponding wavelength of the signal in free space. With that in mind, the velocity factor of the medium must be considered in such calculations to prevent or minimize power loss in calculations.

\section{BACKGROUND OF THE STUDY}

In the applications of transmission lines, the presence of the static VAR compensator can act as a high-power voltage regulator of a device [2]. The static VAR compensator is an electrical device that consists of a set of components that can provide immediate power involving transmission lines with high voltages. Electronic devices that require high amounts of power are commonly used recently because they have a faster dynamic response compared to their counterpart equipment. Static VAR compensators are installed to high-powered electrical devices to improve its power factor while being able to dissipate the negative sequence current it can produce. The static VAR compensator can improve the accuracy of the response time of high-powered devices to reduce mistakes in a power analysis of the device. The static VAR compensator is considered a resistive device which means it is tasked to automatically match impedances to improve the power factor of the device it is connected to. 
Static VAR compensators can also be used in transmission lines to improve the performance of the signals transmitted. One of the applications of static VAR compensator is that it can modulate voltage stability and power limitation [3]. Static VAR compensators can act as controllers that can control multiple variables and components in a power system. The main objective of static VAR compensators is to increase the transmission capacity of long-distance transmission lines and to control the power flowing through designated transmission routes. FACTS controllers can be classified into four categories: series controllers, shunt controllers, combined series-series controllers, and combined shunt-series controllers. The static VAR compensator is a shunt controller that defines its function to act as a generator or absorber of high reactive power while maintaining or controlling a defined parameter of electrical voltage.

\section{STATEMENT OF THE PROBLEM}

We now live in a modern world where electricity is pretty much a necessity. Almost every household makes use of electricity to power up appliances, lights, and electronic devices. Our generation is continuously coming up with new innovations that will be of service to us but also require electricity. Because of this, there is an increase in demand for electric power. Electricity is distributed to each household through transmission lines. Due to the increase in electric power demand, there will need to be more power passing through these transmission lines. They need to be not just long-distance but also have the capability of passing large power through them. Instead of developing new transmission lines that would be very costly and time-consuming, there could be an alternative to eliminate these problems. Static Var Compensators (SVC) are known to provide fast-acting reactive power on high-voltage electricity transmission systems. The study aims to design and simulate a transmission system and show the effects of the SVC with regards to voltage improvement.

\section{SIGNIFICANCE OF THE STUDIES}

The study aims to show how Static Var Compensators (SVC) can help improve the voltage of a transmission system. As stated previously, there is an increase in electric power demand. This demand is large enough that it exceeds the production capacity. Because of this, there is voltage instability present in electric power transmission systems. This is one of the causes of blackouts or power outages. Securing the stability of these electric power systems is essential. The SVC is a part of the Flexible Alternating Current Transmission Systems (FACTS) family. These devices help increase power transfer capability, stability, and controllability of the systems through series and shunt compensation [4]. The SVC is an example of a shunt compensation device.

Showing the effect of these devices through simulation allows us to see their importance in the modern world. New devices may be developed in the future to assist us with difficulties still soon to be encountered. These innovations do not just come to us at our convenience. Continuous study on currently available devices will help as it provides us ideas on how we can still improve them. Small improvements when added up can be significant which can eventually lead to breakthroughs.

\section{DESCRIPTION OF THE SYSTEM}

Figure 1 shows the transmission system model

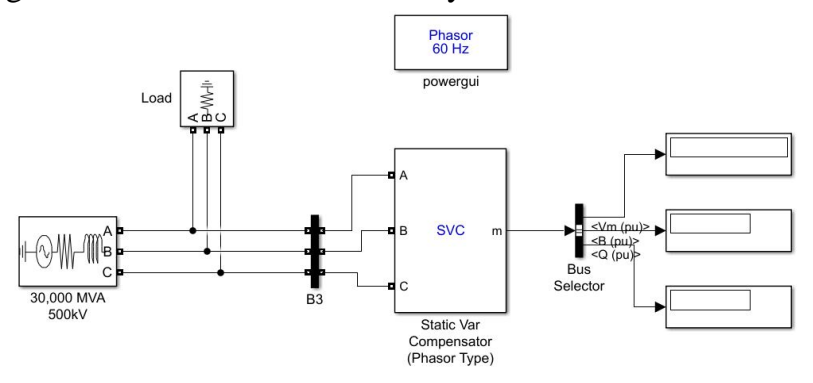

Figure 1: Simulink model of a transmission system to be improved with a Static Var Compensator

Using the different blocks available in MATLAB/Simulink, we were able to design a transmission system with an SVC. This model will then be simulated for us to see the effect of the SVC on the transmission system if there will be any voltage improvements at all. The blocks used in this model include the Three-Phase Source, Three-Phase RLC Load, Static Var Compensator (Phasor Type), Bus Selector, powergui, and Display Blocks.

The transmission system model used in this research is only simple and not very complicated. This is just enough to show the effect of the SVC on the system with regards to voltage improvement. The Three-Phase Source block counts as the voltage source and the transmission line of the system. The Three-Phase RLC Load block counts for the load of the system. The system will be simulated with 4 different values for the load. Data obtained from the 4 cases will be compared and analyzed to arrive at a conclusion regarding the voltage improvement capabilities of the SVC. The Static Var Compensator block will serve as the SVC used in this simulation. The Bus Selector block is used to isolate the different outputs the Static Var Compensator block has. 3 outputs $\mathrm{Vm}(\mathrm{pu}), \mathrm{B}(\mathrm{pu}), \mathrm{Q}(\mathrm{pu})$ will then be connected to display blocks to obtain results.

\section{METHODOLOGY}

Figure 2 shows the Flowchart of the procedure in determining the effect of the SVC on a transmission system. 


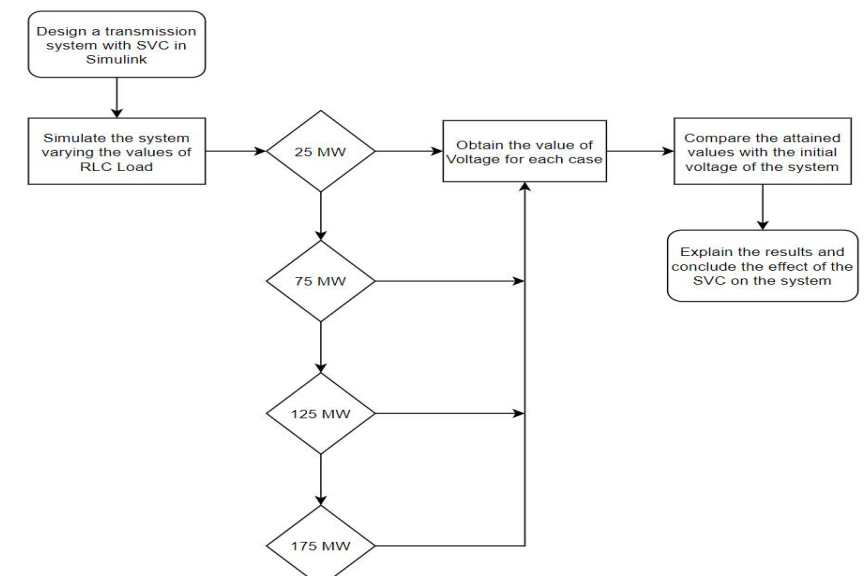

Figure 2: Flowchart of the procedure in determining the effect of the SVC on a transmission system

The design and simulation of the transmission system will be done using MATLAB/Simulink. Blocks used for the system are shown in Figure 1. The values for the Three-Phase Source block should be $500 \mathrm{kV}, 30000 \mathrm{MVA}$, and an X/R ratio of 10 . The values for the Static Var Compensator (phasor type) block should be $200,000 \mathrm{VA}$ for the base power, $+200,000$ VAR and -200,000 VAR for the reactive power limits, and a time delay of $4 \mathrm{~ms}$. The Bus Selector block should select the signals Vm (pu), B (pu), and Q (pu) to pass through from the SVC block. These signals will then be connected to a display block to show their respective values. This is shown in Table 1 .

Table 1: Values of each case of RLC load to be simulated

\begin{tabular}{|c|c|}
\hline Case & Active Power $(\mathbf{W})$ \\
\hline 1 & $25 \mathrm{MW}$ \\
\hline 2 & $75 \mathrm{MW}$ \\
\hline 3 & $125 \mathrm{MW}$ \\
\hline 4 & $175 \mathrm{MW}$ \\
\hline
\end{tabular}

There will be 4 cases for the values of the Three-Phase Series RLC load block. Each case will have an active power of 25 MW, $75 \mathrm{MW}, 125 \mathrm{MW}$, and $175 \mathrm{MW}$ respectively. The reason for varying loads is to obtain data for each case which will help us determine the effect of the SVC on a transmission system. It will also help us analyze the designed transmission system with SVC under different conditions. Results should show that the Static Var Compensator helps improve the voltage properties of a transmission system.

\section{REVIEW OF RELATED LITERATURE}

Renewable energy sources have an important role in the economy because its demand is gradually increasing because the supply for fossil fuels has marginally decreased. One of the most common renewable sources of energy is wind energy because it is clean and efficient no matter the location. The presence of wind is indisputable but converting it to electrical energy is one of the main problems it can encounter. A study conducted by Boynuegri, et al. (2012) [5] regarding the voltage regulation capability of static VAR compensator for wind applications, one of the main difficulties of maintaining large wind farms is that the amount of distributed wind towards each wind turbine may be unequal. With that stated, power distributed to line voltages can vary including that the design of wind turbines will include induction generators. Water turbines can also be used as an alternative for renewable energy sources but unlike wind, water is a crucial resource that may not be available in various locations like in deserts and in places that rain rarely occurs.

Static var systems are an indication of an improvement in modern power systems due to their capability to function as var generation and absorption systems. A study conducted by Kumar and Dave (2005) [6] about the application of static var auxiliary controllers to improve the performance of transmission lines discusses that the importance of an SVS is that it can increase the transmission capability of a power system and can also stabilize it after incurring critical conditions especially involving fragile network systems. Series of static VAR compensators have been used involving transmission lines to enhance the power transfer capability although it is considered to damp the power system oscillations. The researcher was able to identify that various SVS auxiliary controllers can enhance the dynamic and transient performance of long transmission lines. Unstable models were also examined and compared to models that include the SVS auxiliary controllers that led to the conclusion that the presence of these controllers can stabilize the performance of the power systems.

Latest electric power devices such as microprocessors, computers, and electromotor controls are highly dependent on electricity and it requires exceptional quality of power. It is important to take into consideration designing static var compensators to maximize the reduction of power quality issues. According to the journal of Naderipour, et al. (2020) [7] regarding the optimal designing of static var compensator to improve the acquired voltage of a power system, that a static var compensator is an appropriate solution to reduce the power quality on power systems caused by electric arc furnaces. Electric arc furnaces are one of the major causes of problems in power quality but with the help of static var compensators, harmonic currents are reduced significantly and ultimately improved the voltage profile of a power system. The static var compensator acts like a resistive material that is connected to a power system in order to manipulate the voltage by varying the impedance that would result in an optimal design that would improve the quality of the system.

Electrical devices require a specific amount of energy in order to initiate. The start-up of an electronic device is a crucial part because the initial power supplied to the device is not sufficient to initiate the device. A study conducted by Peters, et al. (2010) [8] about the relationship of a static var compensator to a wind turbine discussed the importance of the presence of a fixed speed stall control in a wind turbine especially during its start-up. Start-up transients of a wind turbine connected to a $12.5 \mathrm{kV}$ distribution feeder produced a $900 \mathrm{~kW}$ fixed speed stall. The presence of a static VAR 
Aaron Don M. Africa et al., International Journal of Emerging Trends in Engineering Research, 8(9), September 2020, 5466 - 5471

compensator model added to the wind turbine model underwent the same parameters and the results were able to fix the speed stall and reduce the amount of the start-up transient. This was able to produce a low cost, long lasting, efficient solution to enhance the wind turbine generators to acquire power from a natural element.

With the development of power systems and flexible ac transmission systems, a static var compensator has been used involving the modulation of power systems. In order to identify the advantages of transient stability program and electromagnetic transient program, Zhijun, et al. (2009) [9] tackled the hybrid simulation of power systems with static var dynamic phasor models/ the power systems in the simulations are split into two simulation subsystems through interface buses. The transient stability program simulation tackled the integration step size using a single-phase network model while the electromagnetic transient program simulation involved smaller integration step sizes up to microseconds using a three-phase circuit model. Despite the different simulations, the electromagnetic stability program was performed faster than the transient stability program and the accuracy of the voltage and current waveforms acquired for both simulations were preserved.

\section{THEORETICAL CONSIDERATIONS}

The official MathWorks website states that the Static Var Compensator (phasor type) block in MATLAB/Simulink is a phasor model [10]. This means that it must be used with the phasor simulation method which the powergui block can provide. The SVC can be operated in two different modes: Voltage Regulation Mode and Var Control Mode. Figure 3 shows the V-I characteristic of the SVC.

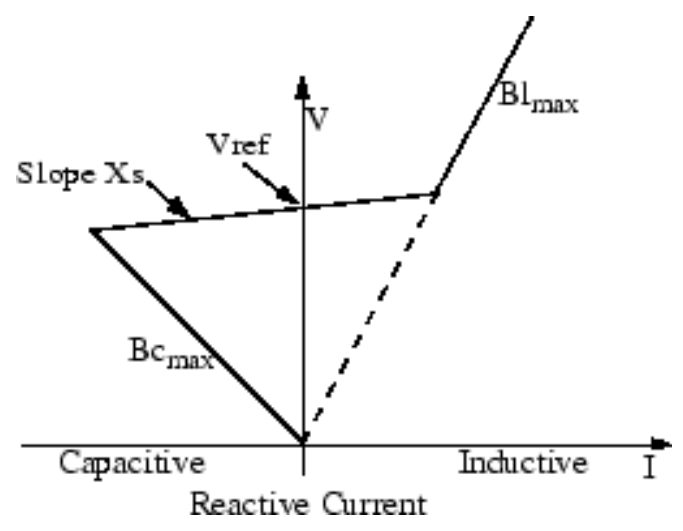

Figure 3: The V-I characteristic of the SVC

When the SVC is operated in Voltage Regulation Mode, it implements the V-I characteristic shown in Figure 3. This shows that as long as the value of B stays within the maximum and minimum susceptance values, the voltage is regulated at the reference voltage. This is shown in table 2 .
Table 2: The six internal signals of the SVC block's output vector $m$

\begin{tabular}{|c|c|c|}
\hline Signal & Signal Group & Signal Names \\
\hline $1-3$ & Power labc $(\mathrm{cmplx})$ & $\mathrm{la}(\mathrm{pu}), \mathrm{lb}(\mathrm{pu}), \mathrm{lc}(\mathrm{pu})$ \\
\hline 4 & Control & $\mathrm{Vm}(\mathrm{pu})$ \\
\hline 5 & Control & $\mathrm{B}(\mathrm{pu})$ \\
\hline 6 & Control & $\mathrm{Q}(\mathrm{pu})$ \\
\hline
\end{tabular}

Previously stated, the SVC block is a phasor model. It has an output vector $\mathrm{m}$ which contains six internal signals. These signals are either voltage-current phasors (complex) or control signals. The respective signals can be accessed by using the Bus selector block. For our simulation, we selected to show the signals: Vm (pu), B (pu), and Q (pu). The signal Vm (pu) shows the positive-sequence value of the measured voltage. The signal B (pu) shows the susceptance output of the voltage regulator. A positive value of $B$ indicates that the SVC is capacitive. The signal $\mathrm{Q}(\mathrm{pu})$ shows the reactive power output. A positive value of $\mathrm{Q}$ indicates that the SVC is inductive.

In the field of Electrical Engineering, pu is an expression of the quantities of a given system as fractions of a defined base unit quantity. This is called a per-unit system and it is used for our transmission model outputs: Vm, B, and Q.

$$
\text { Per unit voltage }=\frac{\text { Actual Voltage }}{\text { Base Voltage }}
$$

Using the per unit voltage equation, plugging in the value of $\mathrm{Vm}(\mathrm{pu})$ for the Per unit voltage while also plugging in the value of our Base Voltage which is $500 \mathrm{kV}$, we can find the Actual Voltage of the system after the SVC is applied. This can be done by multiplying the acquired value of $\mathrm{Vm}(\mathrm{pu})$ and the Base Voltage.

\section{DATA AND RESULTS}

Figures 4 to 7 shows the output of the system's simulation.

Note: Output displays are cropped from the whole transmission system model to give emphasis on the display blocks.

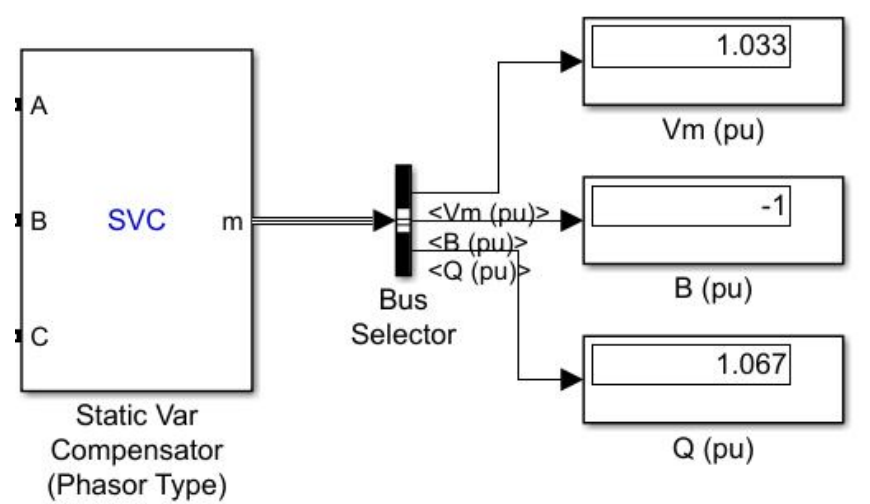

Figure 4: Output display of Case 1 simulation 


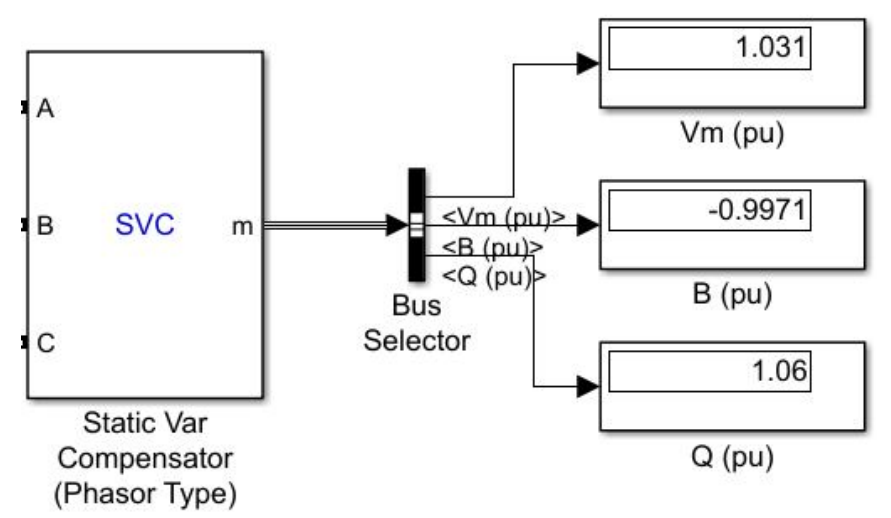

Figure 5:Output display of Case 2 simulation

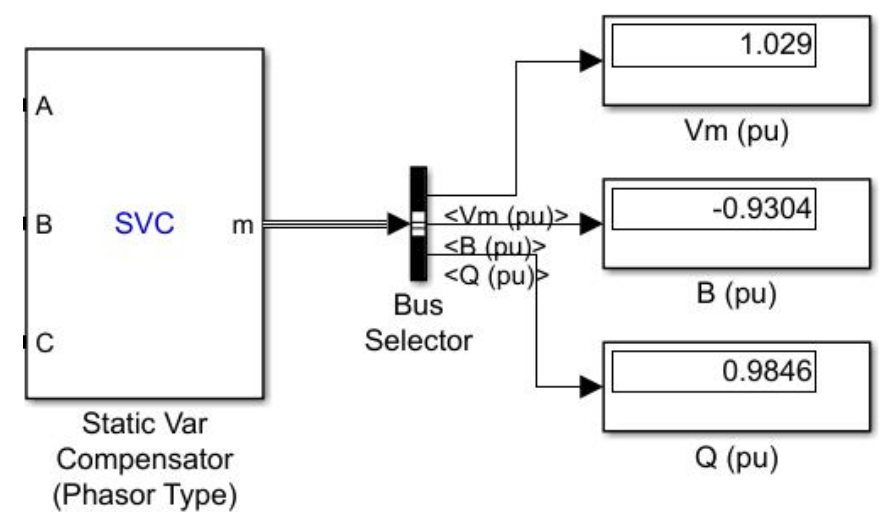

Figure 6:Output display of Case 3 simulation

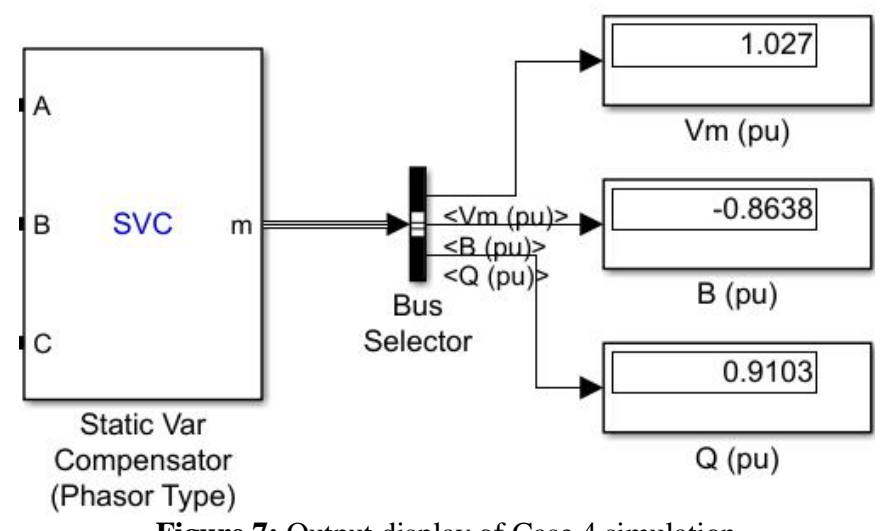

Figure 7: Output display of Case 4 simulation

The simulation was able to show 3 unique outputs for each of the 4 varying load cases: $25 \mathrm{MW}, 75 \mathrm{MW}, 125 \mathrm{MW}$, and 175 MW. These outputs are the signals Vm (pu), B (pu), Q (pu). The summary of this is shown in table 3 .

Table 3: Summary of the outputs for each case

\begin{tabular}{|c|c|c|c|}
\hline Case (load) & Vm $(\mathrm{pu})$ & $\mathrm{B}(\mathrm{pu})$ & $\mathrm{Q}(\mathrm{pu})$ \\
\hline $25 \mathrm{MW}$ & 1.033 & -1 & 1.067 \\
\hline $75 \mathrm{MW}$ & 1.031 & -0.9971 & 1.06 \\
\hline $125 \mathrm{MW}$ & 1.029 & -0.9304 & 0.9846 \\
\hline $175 \mathrm{MW}$ & 1.027 & -0.8638 & 0.9103 \\
\hline
\end{tabular}

\section{ANALYSIS OF DATA}

The data gathered from the simulation shows a positive value of Q for all cases. This indicates that the SVC in this system is inductive. This also means that the reactive power of the system is lagging. Looking at the values of $\mathrm{Vm}(\mathrm{pu})$ for each case, we can use equation 1 in finding the actual voltage for each case.

Case 1: $1.033=\frac{\text { Actual Voltage }}{500 \mathrm{kV}}$

Case 2: $\quad 1.031=\frac{\text { Actual Voltage }}{500 \mathrm{kV}}$

Case 3: $1.029=\frac{\text { Actual Voltage }}{500 \mathrm{kV}}$

Case 4: $\quad 1.027=\frac{\text { Actual Voltage }}{500 \mathrm{kV}}$

Cases 1 to 4 are used in solving for the Actual Voltage allows us to see the voltage improvement in each case. This can be done by multiplying the Base voltage which is $500 \mathrm{kV}$ to the value of $\mathrm{Vm}(\mathrm{pu})$ of each case. The voltage improvement of the cases is shown in table 4 .

Table 4: Voltage improvement of each of the 4 cases of simulation

\begin{tabular}{|c|c|c|}
\hline Load & Base Voltage & Voltage Improvement \\
\hline $25 \mathrm{MW}$ & $500 \mathrm{kV}$ & $516.5 \mathrm{kV}$ \\
\hline $75 \mathrm{MW}$ & $500 \mathrm{kV}$ & $515.5 \mathrm{kV}$ \\
\hline $125 \mathrm{MW}$ & $500 \mathrm{kV}$ & $514.5 \mathrm{kV}$ \\
\hline $175 \mathrm{MW}$ & $500 \mathrm{kV}$ & $513.5 \mathrm{kV}$ \\
\hline
\end{tabular}

In Table 4 we are able to see the voltage improvement of the transmission system due to the SVC. There is no significant drop in the value of voltage improvement as the value of the load increases. This indicates that the SVC is indeed an effective device to help regulate the voltage in a transmission system and secure the system's voltage stability.

\section{CONCLUSION}

A transmission system to be improved by a Static Var Compensator (SVC) was designed and simulated in MATLAB/Simulink. There were 4 cases of simulation of which data was obtained from. These 4 cases were the variation of the Three-Phase Series RLC load. Results show an improvement of voltage in the transmission system due to the SVC.

The values of B and Q seen from Table 3 indicate that the SVC is operating inductively. This means that the system voltage is high as it absorbs reactive power from the system. The SVC can also operate capacitively where if the system voltage is low, it generates reactive power for the system. 
Flexible Alternating Current Transmission Systems (FACTS) are devices known to help transmission systems with regards to power transfer capability, stability, and controllability. The SVC, being a shunt compensation FACTS device, was shown in this study its effect on our designed transmission system. We were able to show that these devices really do help in improving the voltage of transmission systems $[11,12]$.

\section{RECOMMENDATIONS}

The design and simulation of the transmission system in this study is only simple enough to show the effect of the SVC. Because of this, it is recommended to add some depth to the design of the system. Future studies may consider adding Reactive Power with the unit MVar to the load. This value may be capacitive or inductive. Our study only makes use of Active Power with the unit MW for the load. Making the transmission system as close as possible to current standards will allow future studies to be new and relevant in the academe especially in the field of Electrical Engineering.

Researches on the design and modelling of transmission systems with Flexible Alternating Current Transmission Systems (FACTS) devices allow new members of the field to see the effect of these devices on how they can help improve different transmission systems. It can also help experienced members of the field to provide them ideas for even more new and up to date studies.

\section{REFERENCES}

[1] M. Löschenbrand, "A transmission expansion model for dynamic operation of flexible demand," International Journal of Electrical Power \& Energy Systems, Vol. 124, 2021.

[2] C. Zhang, Q. Jiang, and S. Sun, "The Research of Static Var Compensator's Time Characteristics and System-level Model of Controlled Current Source," Physics Procedia, Vol. 24, Part A, pp. 198-204, 2012.

[3] H. Guillardi, E. Verri Liberado, J. Pomilio, F. Marafão, "General-compensation-purpose Static var Compensator prototype," HardwareX, Vol. 5, 2019.

[4] A. Singh, B. Pal, "Dynamic Estimation and Control of Power Systems,” Academic Press, pp. 1-8, 2019.

[5] A.R. Boynuegri, B. Vural, A. Tascikaraoglu, M. Uzunoglu, R. Yumurtac1, "Voltage regulation capability of a prototype Static VAr Compensator for wind applications," Applied Energy, Vol. 93, pp. 422-431, 2012.

[6] N. Kumar, M.P. Dave, "Application of static var system auxiliary controllers to improve the transient performance of series compensated long transmission lines," Electric Power Systems Research, Vol. 34, no. 2, pp. 75-83 2005.

[7] A. Naderipour, Z. Abdul-Malek, F. Gandoman, S. Nowdeh, M. Shiran, M. Moghaddam, and I. Davoodkhani, "Optimal designing of static var compensator to improve voltage profile of power system using fuzzy logic control," Energy, Vol. 192, 2020.

[8] R. Peters, D. Muthumuni, T. Bartel, H. Salehfar, M. Mann, "Static VAR compensation of a fixed speed stall control wind turbine during start-up," Electric Power Systems Research, Volume 80, No. 4, pp. 400-405, 2010.

[9] E Zhijun, D.Z. Fang, K.W. Chan, S.Q. Yuan, "Hybrid simulation of power systems with SVC dynamic phasor model," International Journal of Electrical Power \& Energy Systems, Vol. 31, No. 5, pp. 175-180, 2009.

[10] Matlab. $\quad$ https://www.mathworks.com /products/matlab.html. 2020.

[11] A. Africa, "Development of a wave propagation model in a lossy transmission line," International Journal of Emerging Trends in Engineering Research, Vol. 8, No. 7, pp. 3351-3357, 2020.

[12]E. Altimimee and H. Abduljalil, "Electronic transmission stability in pyrene derivatives," International Journal of Emerging Trends in Engineering Research, Vol. 8, No. 4, pp. 1457-1459, 2020. 